\title{
EFFECT OF SPIRAL GROOVES IN PISTON BOWL ON EXHAUST EMISSIONS OF DIRECT INJECTION DIESEL ENGINE
}

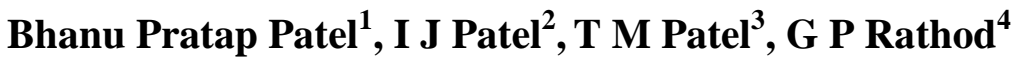 \\ ${ }^{1}$ M.E Student, Mechanical Engineering Department, L.J.I.E.T, Ahmedabad, Gujrat, India \\ ${ }^{2}$ Professor, Mechanical Engineering Department, L.J.I.E.T, Ahmedabad, Gujrat, India \\ ${ }^{3}$ Associate Professor, Mechanical Engineering Department, L.D.R.P Institute of Technology and Research Gandhinagar, \\ Gujrat, India \\ ${ }^{4}$ Assistant Professor, Mechanical Engineering Department, L.D.R.P Institute of Technology and Research Gandhinagar, \\ Gujrat, India
}

\begin{abstract}
In present time developed and developing country are used from small to largest diesel engine as a power plant for different purpose like generating electricity and transportation. These engines consume in heavy quantity fuel per hour, where these engines produce the bulk power as well as there also produce the different types of toxic gases that harmful our human beings and environment. At this time both type of country try to reduce the harmful gases from diesel engine In present scenario many technology are used to reduce the toxicity of exhaust gases EGR (Exhaust Gas Recirculation) is one of them. Where EGR reduces the toxicity of exhaust gases and fuel consumption as well as their reduce the power of engine which is not good at any level. In this present experimental work to reduce the $\mathrm{NOx}, \mathrm{HC}, \mathrm{CO}$, and $\mathrm{CO}_{2}$ some modification has been done in piston bowl by cutting three spiral grooves on inner surface of hemispherical bowl and slight increasing in bowl diameter. The spiral grooves increase the air capacity and slight reduce the compression ratio as well as make homogeneous mixing of air and fuel.This experiment is done on Kirloskar AVl water cooled, natural aspirated direct injection diesel engine with pure diesel. In experiment it is observed the fuel consumption and NOx reduction by $0.1 \mathrm{Kg}$ per hour $8.82 \%$. respectively.
\end{abstract}

Keywords: D.I.Diesel Engine, Spiral Grooved Piston, Swirl, Emissions

****

\section{INTRODUCTION}

Environmental pollution at this time is very serious problem for our human beings and flora-fauna. Our environment is polluted day by day from industrial emissions and road vehicles emissions. Petrol engine and diesel engine produced different types of harmful gases during combustion like NOx, $\mathrm{CO}, \mathrm{CO}_{2}, \mathrm{HC}$ and some quantity $\mathrm{SOx}$ due to poor fuel quality. These gases are produced by different engine factor such as piston bowl geometry ,injection timing, compression ratio etc. All these factor also affects the combustion efficiency, fuel consumption and engine brake power.

To reduce the emissions engine manufacturers try to best design the combustion chamber and other level. At combustion chamber geometry design to reduce the NOx many researchers studied the different piston bowl geometry. $\mathrm{Cao} \mathrm{Li}$ et al reported the $\mathrm{NO}$ and $\mathrm{CO}$ emission are lower for the vertical wall bowl shape and Re- entry bowl shape as comparison to open bowl shape [14]. In numerical study of NOx reduction Liu found the NO can be reduced by changing the bowl depth [13]. By theoretical investigation Risi.A.De. et al also reported lower NOx emission for different piston bowl shape at higher speed [12].In experimental study of tangential grooves on piston crown by Reddy .C.V et al also reported the lower $\mathrm{CO}$ emission for different fuels[11].

So, in current scenario every researcher and manufacturers try to reduce the exhaust emissions by combustion chamber design as well as other method like EGR (Exhaust Gas Recirculation), SCR (Selective Catalytic Reactor) and HCCI ( Homogeneous Charge Compression Ignition). Here in present work NOx and other gases are reduced by the modification of piston bowl geometry for direct injection diesel engine.

\section{EXPERIMENTAL SETUP}

To measure the NOx and other exhaust gases like $\mathrm{CO}, \mathrm{CO}_{2}$ and $\mathrm{HC}$ the experiments are conducted on single cylinder four stroke water cooled direct injection diesel engine Kirloskar AV1 engine .To measure the exhaust gases ARO, Quattro Pro GA-4050 five gas analyser is used. Detail specifications of engine setup and gas analyser are given in table (1) and table (2). 


\subsection{Specifications of Diesel Engine and Rope Brake}

\section{Dynamometer}

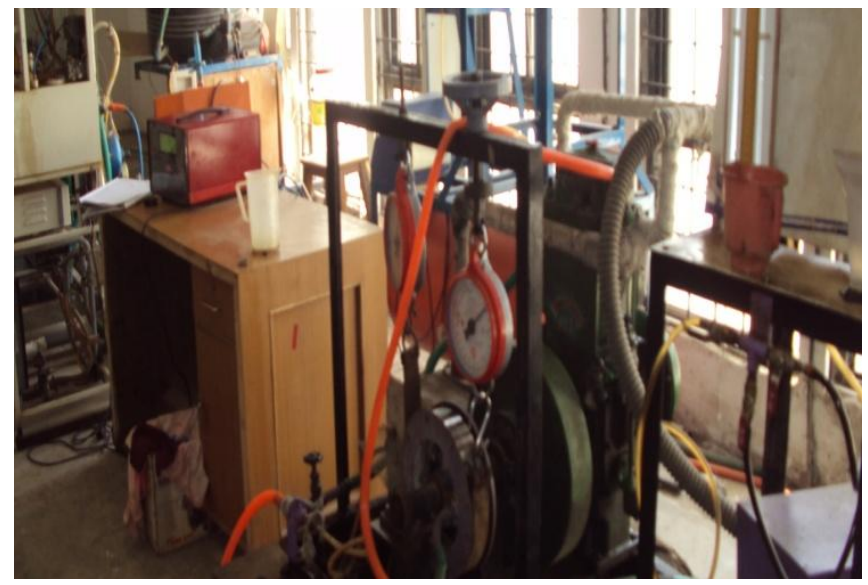

Fig 1

Table 1

\begin{tabular}{|l|l|}
\hline Item & Specification \\
\hline $\begin{array}{l}\text { Kirloskar Diesel Engine } \\
\text { Model }\end{array}$ & AV1 \\
\hline Engine power & $3.7 \mathrm{KW}$ \\
\hline Cylinder Bore & $80 \mathrm{~mm}$ \\
\hline Stroke Length & $110 \mathrm{~mm}$ \\
\hline Engine Speed & $1500 \mathrm{rpm}$ \\
\hline Compression Ratio & $16.5: 1$ \\
\hline Swept volume & $553 \mathrm{cc}$ \\
\hline Stroke & Four \\
\hline Injection Pressure & $190 \mathrm{bar}$ \\
\hline Injection Timing & $27^{0} \mathrm{~b}$ TDC \\
\hline $\begin{array}{l}\text { Number of hole of injector } \\
\text { and size }\end{array}$ & Three x $0.25 \mathrm{~mm}$ \\
\hline Dynamometer & Rope Brake Type \\
\hline Diameter of Brake Pulley & $30 \mathrm{~mm}$ \\
\hline
\end{tabular}

\subsection{Specifications of Gas Analyser}

Table 2

\begin{tabular}{|l|l|l|l|l|}
\hline \multicolumn{5}{|c|}{ ARO, Quattro Pro GA-4050 Five gas Analyzer } \\
\hline \hline Gases & $\begin{array}{l}\text { Specified } \\
\text { Range }\end{array}$ & $\begin{array}{l}\text { Accuracy } \\
\text { Volume }\end{array}$ & Accuracy & Resolution \\
\hline $\mathrm{CO}$ & $0-10 \%$ & $0.06 \%$ & $3 \%$ & $0.01 \%$ \\
\hline $\mathrm{CO}_{2}$ & $0-20 \%$ & $0.4 \%$ & $4 \%$ & $0.1 \%$ \\
\hline $\mathrm{HC}$ & $\begin{array}{l}0-20000 \\
\text { ppm }\end{array}$ & $12 \mathrm{ppm}$ & $5 \%$ & $1 \mathrm{ppm}$ \\
\hline $\mathrm{O}$ & $0-21 \%$ & $0.1 \%$ & $3 \%$ & $0.01 \%$ \\
\hline $\mathrm{NO}$ & $\begin{array}{l}0-5000 \\
\text { ppm }\end{array}$ & $25 \mathrm{ppm}$ & $5 \%$ & $1 \mathrm{ppm}$ \\
\hline
\end{tabular}

\subsection{Modified Piston}

In modified piston three spiral grooves has been made on inner surface of hemispherical bowl piston and slight increasing in piston bowl diameter .The spiral grooves make homogeneous mixing of air and fuel during combustion by enhancing the swirl within combustion chamber and increased bowl diameter decrease the compression ratio and its effect on emission reduction are observed. In figure (2) both piston are presented with section view.

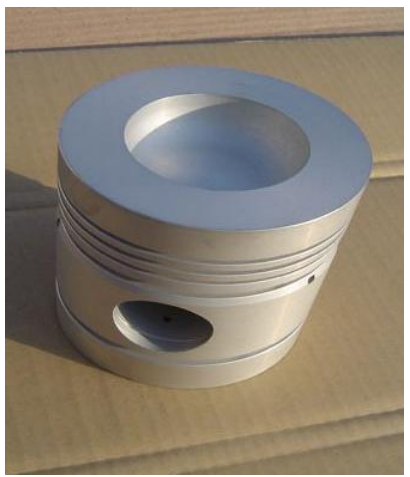

Standard Piston

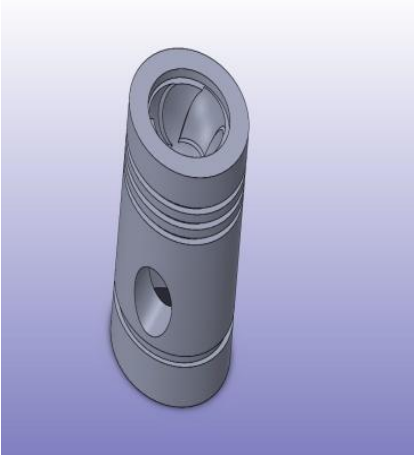

Modified Piston

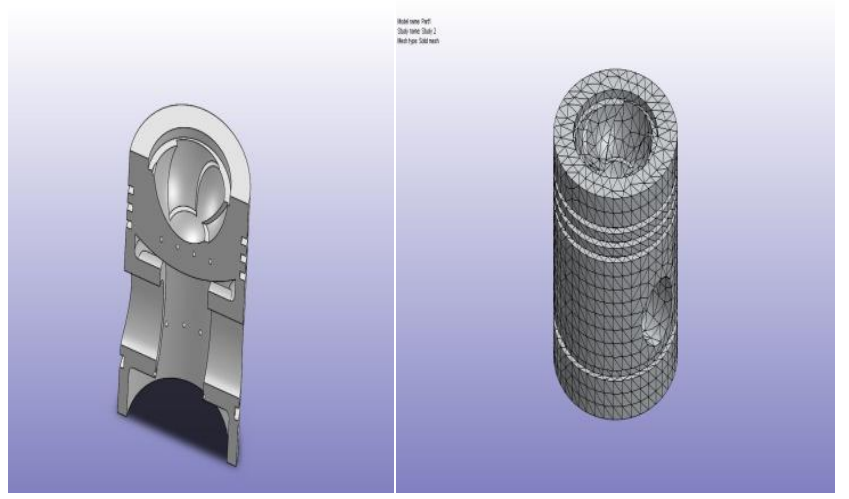

Fig 2 Piston Section View

Meshing of Piston

\subsection{Experimental Procedure}

The experiment are performed on D.I .Diesel Engine at constant speed $1500 \mathrm{rpm}$ with injection pressure 190 bar by using pure diesel. In first phase the data recorded with standard piston (hemispherical bowl shape) and in second phase the data recorded by changing the modified piston ( spiral grooved piston). The power of engine is measured by the rope brake dynamometer that is coupled with engine and engine exhaust emission are measured by ARO five gas analyser at different load. The performance and emission characteristic are compared with standard piston results. 


\section{RESULTS AND DISCUSSION}

\subsection{Brake Thermal Efficiency}

Since brake thermal efficiency of engine depends on different engine factors like engine piston bowl shape. Here in modified piston the spiral grooves make homogeneous mixing of air and fuel that amplify the combustion efficiency .In figure 3 the comparison is shown with respect to brake power of engine. In this experiment we the $24.3 \%$ for the standard piston and $26.2 \%$ for modified piston, in this way at full load of engine the increment in brake thermal efficiency is $1.9 \%$.

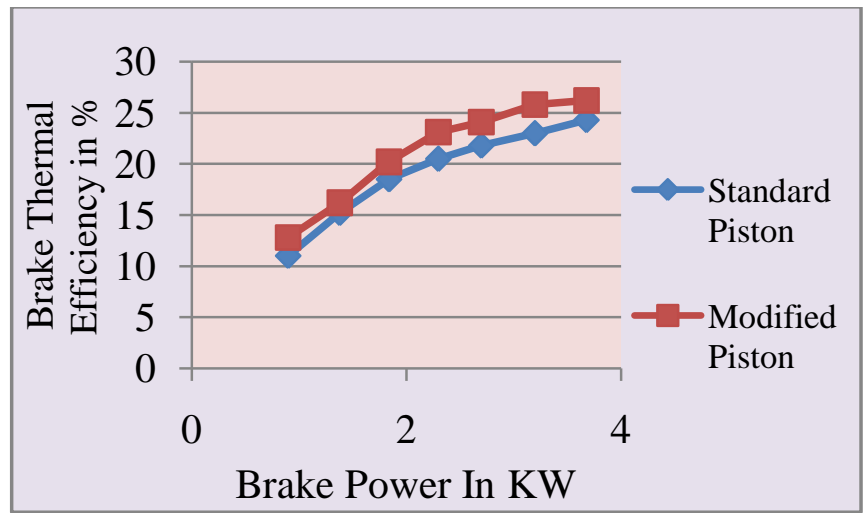

Fig .3 Brake Power vs Brake Thermal Efficiency

\subsection{Brake Specific Fuel Consumption}

In figure 4 the comparison of BSFC for the two pistons with respect to engine brake power are presented. From figure it can be observed that as the engine load increases the BSFC reduces respectively. But for modified piston the BSFC slightly more reduced at full load than Standard Piston. The BSFC reducing showed the lower fuel consumption that is fuel economy.

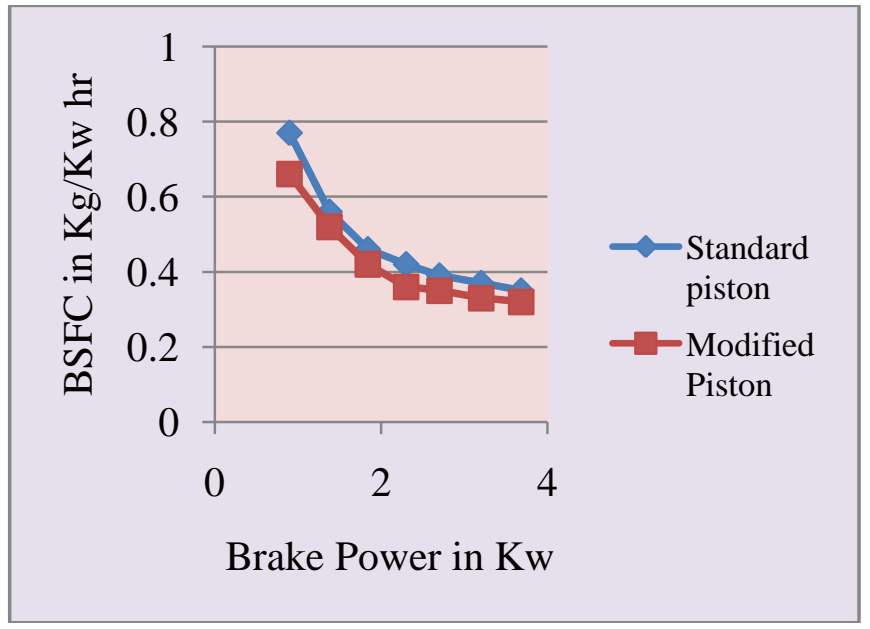

Fig.4 Brake Power vs BSFC

\subsection{Nitrogen Oxides}

NOx emission from engine depends on various factor like compression ratio, temperature, piston bowl shape, and injection pressure etc. Here in modified piston the spiral grooves slightly reduced the compression ratio that regulates the peak temperature of combustion and homogeneous mixing help to decreasing the NOx during the combustion. It is observed that the NOx is reduced by $8.82 \%$ at full engine load.

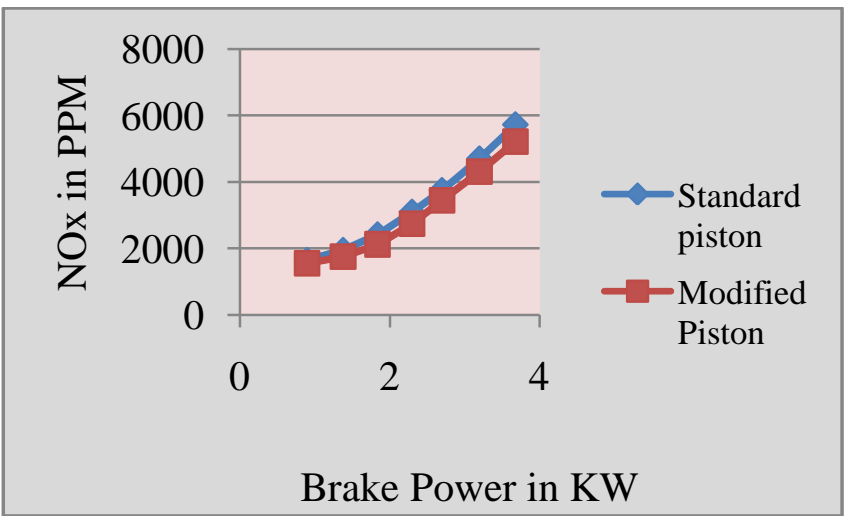

Fig.5 Brake Power vs $\mathrm{NO}_{\mathrm{x}}$

\subsection{Hydrocarbon Emission}

Hydrocarbon emission reduction at full load significantly not much lower than standard piston. However it is reduced by 4.6 $\%$ for modified piston.

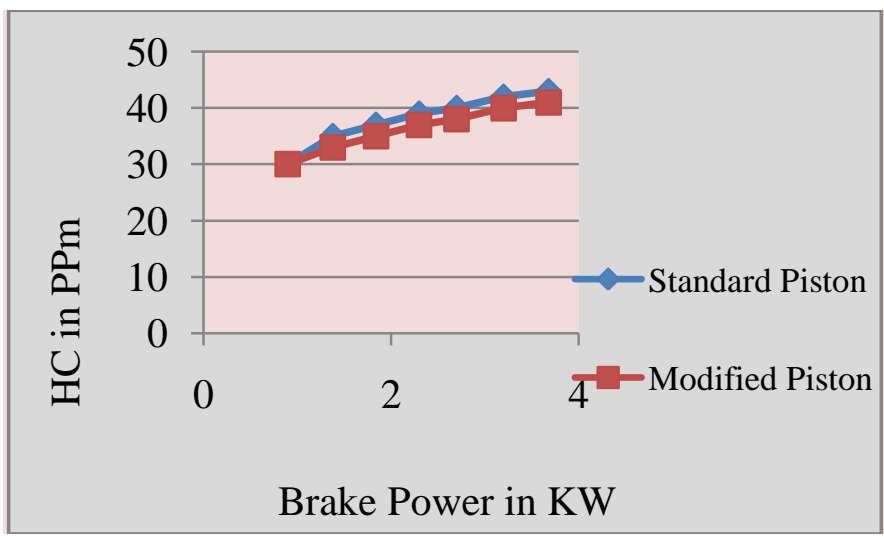

Fig.6 Brake Power vs HC

\subsection{Carbon Monoxide}

The reduction in carbon monoxide for modified piston is observed near about $7.7 \%$ than standard piston. The $\mathrm{CO}$ reduction is not more as many possible but spiral grooves helps better mixing of air and fuel during combustion. 


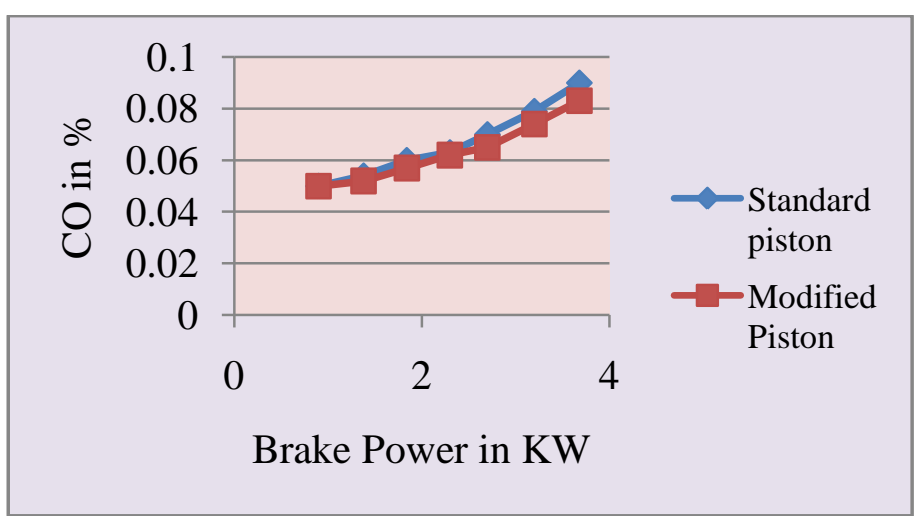

Fig.7 Brake Power vs CO

\subsection{Exhaust Gas Temperature}

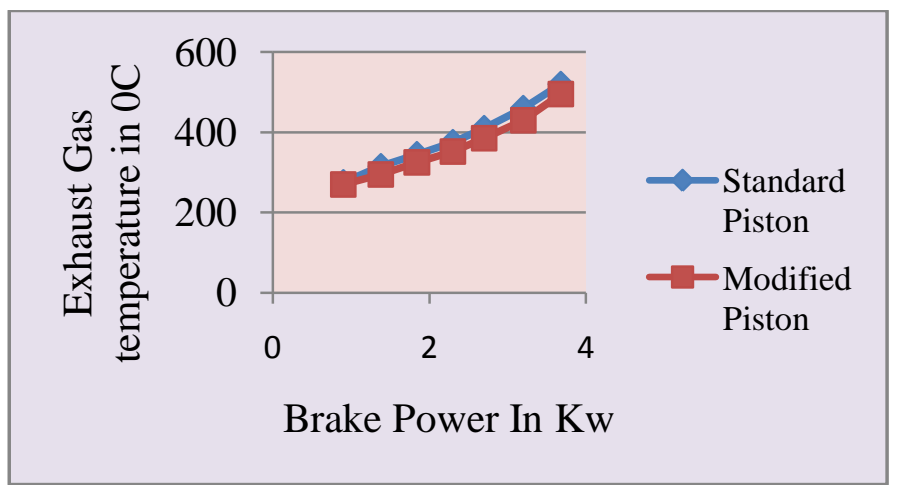

Fig .8 Brake power vs Exhaust Gas Temperature

During experiment it observed that as the engine load increasing the exhaust gas temperature also increases. For standard piston the maximum exhaust gas temperature is 520 ${ }^{0} \mathrm{C}$ at full load and for modified piston the maximum exhaust gas temperature is $495^{\circ} \mathrm{C}$ which is lower than standard piston . The spiral grooves affects turbulence and swirl within combustion chamber and cause the reduction of gas temperature that is lower cooling requirement and safe operation as well as NOx reduction. In figure 10.7 the comparison is shown for both piston and temperature reduction by $4.8 \%$.

\section{CONCLUSIONS}

It is observed from experiments as the engine load increases

1 - The fuel consumption slightly reduced by $0.1 \mathrm{Kg}$ per hour.

2- Brake thermal efficiency for modified piston is increased near about $1.9 \& 2 \%$.

3 - Brake specific Fuel Consumption is also reduced.

4- NOx is reduced by $8.82 \%$ at full engine Load.

5- $\mathrm{HC}$ is reduced but not significantly as many possible.

6- $\mathrm{CO}$ is also reduced but not much more as expected.

7- The temperature of exhaust gas is reduced by $4.8 \%$.

\section{FUTURE SCOPE}

Spiral grooves in piston bowl enhances the air swirl within combustion chamber as well as increases the air capacityduring suction and slightly reduces the compression ratio that controlled the peak temperature during combustion. By this way fuel consumption and NOx are reduced. However, further investigations are required for turbulence during compression stroke, HCCI combustion and injection parameters like injection timing and injection pressure to improve the present work.

\section{REFERENCES}

[1]. Agarwal. A.K ;Singh. A.P ; Lukose Jithin ; Gupta tarun ; “ Charecterization of Exhaust Particulates from Diesel Fueled Homogeneous charge Compression Ignition Combustion Engine" Journal of Aerosol Science ; 58 (2013) 71-85.

[2]. Curtis .E.W; Uludogan.A; and Reitz .R.D; “ A New Pressure Droplet Vaporization Model for Diesel Engine Modeling"; SAE Technical Paper 952431; 01-10-1995.

[3]. Genazale .C ; Wickman .D and Reitz R.D; “ An Advanced Optimization Methodology for Understanding the Effects of piston Bowl Design in Late Injection Low- temperature Diesel Combustion"

[4]. Kim .Y.J; and et al " Effect of a 2- Stage Injection Strategy on the Combustion and Flame Characteristic in a PCCI Engine"International Journal of Automotive Technology Vol.12 ,No. 5 , pp. 633- 644, 2011.

[5]. Song. Jinou, ; Yao. Chunde and et al ; "Investigation on Flow Field in Simplified Piston Bowls for DI Diesel Engine" Engineering applications of Computational Fluid mechanics Vol. 2, No. 3, pp. 354-365 , 2008.

[6]. Choi. Gyeung Ho; Lee.Jae Cheon and et al; "Combustion Characteristics of a Swirl chamber Type Diesel engine" Journal of Mechanical Science and Technology 23 , pp. 33853392, 2009.

[7]. Han Zhiyu; Uludogan Ali and et al ; “Mechanism of Soot and NOx Emission Reduction Using Multiple - injection in a Diesel Engine" SAE Technical Paper 960633, 1996.

[8]. Uludogan .A; Xin.J and Reitz.R.D ; " Exploring the use of Multiple Injectors and Split Injection to Reduce DI Diesel Engine Emissions" SAE Technical Paper 962058; 1996.

[9]. Gabrielsson pär and et al "Combined Silencers and UreaSCR Systems for heavy -duty Diesel Vehicles for OEM and Retrofit Markets" SAE Technical Papers 0517, 2001.

[10]. Murotani Taisuke ; Hattori .k and et al "Simultaneous Reduction of NOx and Soot in a Heavy - Duty Diesel Engine by Instantaneous Mixing of Fuel and Water" SAE Technical Papers 0125, 2007.

[11]. Reddy .C.V ;Reddy.C.E and et al "Effect of Tangential Grooves on Piston Crown of D.I Diesel Engine with Blends of Cotton Seed Oil Methyl Easter" IJRRAS , Vol . 13 , Issue $1,2012$.

[12]. Risi A.De, Manieri .D.F and Laforgia .D “ A Theoretical Investigation on the Effects of Combustion Chamber Geometry and Engine Speed on Soot and NOx Emissions" 
[13]. Liu Renshan and Zhang Chao “ A Numerical Study of NOx Reduction for a DI Diesel Engine with Complex Geometry"Journal of Energy Resources Technology D.O.I 10.1115/1.1627366. , 2002.

[14]. Cao.Li ; Bhave Amit and et al "Influence of injection Timing and Piston Bowl Geometry on PCCI Combustion and Emissions" SAE Technical papers 2009-01- 1102.

\section{BIOGRAPHIES}

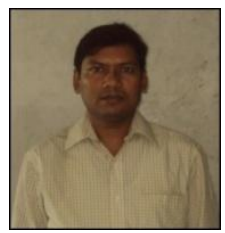

Bhanu Pratap Patel, student of master of engineering (Thermal Engg.) at LJIET Ahmedabad affiliated to Gujarat Technological University Ahmedabad Gujrat.

Email: pratapbhanumech@gmail.com

Mo.NO. +91-9721696954

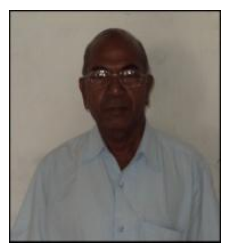

Prof. I.J.Patel is currently professor of mechanical engineering at LJIET Ahmedabad affiliated to Gujarat Technological University Ahmedabad Gujrat. He has experience 37 years of teaching .

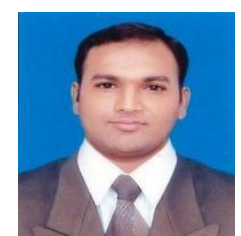

Prof. T.M.Patel*(Corresponding Author) is currently associate professor of mechanical engineering at LDRP Institute of Technology and research Gandhinagar Gujarat. He has experience 14 years of teaching. $\mathrm{He}$ is pursuing PHD and his research areas are IC Engine/Automobile Email: tushar.modasa@gmail.com

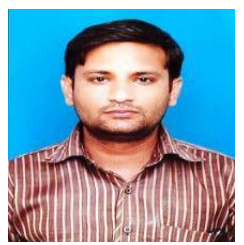

Prof. G.P.Rathod is currently assistant professor mechanical engineering at LDRP Institute of Technology and research Gandhinagar Gujarat. He has experience 6 years of teaching.

Email: gy_rathod@yahoo.co.in 